\title{
JURISPRUDENCIA DEL TRIBUNAL \\ SUPREMO SOBRE DESPIDOS COLECTIVOS: ACTUALIZACIÓN E INTERPRETACIÓN JUDICIAL
}

\author{
Adiran Benito-Butrón González \\ Grado en Derecho \\ Erasmus, Università degli Studi di Salerno
}

DOI: $10.1387 /$ lan-harremanak.15395

\section{ABSTRACT}

Se trata de recopilar "todas» las sentencias de nuestro TS con pronunciamientos en materia de despido colectivo tras la profunda reforma habida por RDL 3 y Ley 3/2012, siguiendo en esquema de temáticas y materias que esbozo.

Palabras clave: despido colectivo, Tribunal Supremo, causas, derechos fundamentales, grupos, nulidad.

Lan honen asmoa Auzitegi Gorenak, 3/2012 Errege Lege Dekretu eta 3/2012 Legeek ekarritako erreforma sakonaren ostean, Kaleratze Kolektiboaren inguruan emandako epaien bilketa egitea da.

Gako hitzak: kaleratze kolektiboa, Auzitegi Gorena, arrazoiak, oinarrizko eskubideak, taldeak, deuseztasuna.

The purpose of this work is to collect the judgments of the Supreme Court about Collective Dismissal after the reform caused by RDL 3/2012 and Law 3/2012.

Key Words: collective dismissal, Supreme Court, causes, fundamental rights, groups, nullity. 


\section{Noción de despido colectivo}

\section{1.` ELEMENTO NUMÉRICO-TEMPORAL}

a) Número de trabajadores despedidos y número de trabajadores de la empresa (STS 23-5-13, 179/13(TS 21-5-14, Rec. 17/14). Ver también luego (Despido Colectivo de Hecho) el comentario de la STS de 18 de noviembre de 2014 (RC 65/2014).

b) Extinciones computables: 1) despidos disciplinarios cuya improcedencia haya sido reconocida por el empresario en transacción judicial o extrajudicial, al estimarse que se trata de extinciones acordadas a iniciativa suya y por motivos no inherentes a la persona del trabajador, que no se convierten en extinciones por mutuo acuerdo al margen de la intervención del empleador (STS 25-11-13, Rec. 52/13 y 26-11-13, Rec. 334/13); 2) ese mismo razonamiento llevaría a computar los despidos objetivos fundados en el art. 52, letras a), b), y d) ET, en los que concurra esa circunstancia; 3) extinciones por causas objetivas acordadas al amparo de art. 52.c) ET por causas distintas de las alegadas; y ello, aunque los afectados hayan firmado documentos de finiquito, aceptando el efecto extintivo mediante acuerdos de naturaleza transaccional lo que no las transforma en dimisiones al margen de la voluntad del empresario (STS 25-11-13, Rec. 52/13), o del art. 52.e) ET. 4) extinción de los contratos de los trabajadores indefinidos no fijos al servicio de las Administraciones Públicas (STS 24-6-14, Rec. 217/13); 5) Extinciones de contratos temporales cuando hayan sido reconocidas como despido improcedentes en acto de conciliación administrativa o procesal, o exista un panorama indiciario suficiente del carácter irregular de su suscripción o de que han finalizado antes de la llegada de su términos (STS 3-7-12 (dos), Rec. $1657 / 11$ y 1744/11; 8-7-12, Rec. 2341/12; 24-6-14, Rec. 217/13). Las extinciones regulares de contratos temporales lícitos quedan excluidas del cómputo por mandato legal (art. 51.1.4. ${ }^{\circ}$ ET cuya eventual contradicción con la Directiva ha sido denunciada también por el JS 33 de Barcelona en el auto anteriormente citado). Carga de la prueba del empresario (STS 23-4 2012 R. 2724/11)

La STS de 9 de julio de 2014 (RCUD 1767/2012). Ratifica la procedencia del despido efectuado al amparo del art. 52.c) ET (y no su nulidad), ya que no se alcanzan los umbrales numéricos propios del despido colectivo (art. 51.1 ET), al estar ante una empresa de más de trescientos trabajadores, siendo veintiséis las 
extinciones similares efectuadas en los noventa días anteriores, sin que puedan computarse las efectuadas con posterioridad (constaban otras cincuenta ocho en los dos meses siguientes, de las que dieciséis lo fueron cuatro días después), al no constar que estas se hicieran en fraude de ley. La sentencia se hace eco de la doctrina iniciada en STS de 23-Ab-12 (RCUD 2724/2011) y seguida por las de 23-En-13 (RCUD 1362/2012) y 9-Ab-14 (RCUD 2022/2013).

c) Período de referencia para el cómputo de las extinciones (STS 23-412, Rec. 2724/11; 23-1-13 Rec. 1362/12; 28-10-13, Rec. 2689/12; 11-2-14, Rec. 323/13; 9-4-14, Rec. 2022/13; y 9-7-14, Rec. 1767/12).

2. ELEMENTO CAUSAL (TS 8-7-12, Rec. 2341/12 y 3-7-12 -dosRec. 1744/11 y 1657/11); o los despidos disciplinarios en masa (TSJ Madrid 12-3-12, Rec. 5911/11); o los ceses por finalización de la contrata sin que se haya producido su conclusión (TSJ Burgos 8-10-13, Rec. 478/13; 27-6-13, Rec. 248/13 y 10-4-13, Rec. 146/13), o aun habiendo terminado, cuando no exista obligación de subrogación (TSJ Madrid 4-10-13, autos 1669/13 y 29-7-13, autos 28/13). STS 22-7-2013 R. 1380/12 y 24-6-2014 R. 217/13 (Caso U. Politécnica).

Despido colectivo de hecho: STS 25-11-13, Rec. 52/13 y la STS de 18 de noviembre de 2014 (RC 65/2014). Sala General. 1) Los despidos disciplinarios reconocidos como improcedentes son computables a efectos de determinar si se han superado los umbrales propios de un despido colectivo; 2) es despido colectivo de hecho, nulo conforme al art. 124.11 LJS, el efectuado por Unísono Soluciones de Negocio SA, dado el número de extinciones computables a estos efectos, a iniciativa empresarial, producidos entre el 1 de febrero y el 30 de abril de 2013, que rebasan los umbrales del art. $51.1 \mathrm{ET}$ (en el caso, constaban 16 ex art. 52.c ET entre el 1-Fb y 23-Mz-13; 12 ex art. 52.d entre el 1 de febrero y el 7 de marzo; y 34 despidos disciplinarios producidos entre el 1 de febrero y 30 de abril, aunque sin precisar fecha, reconocidos como improcedentes); 3) corresponde a la empresa, conforme al art. 217 LEC, la carga de la prueba del momento en que se produce un despido colectivo "de hecho", a efectos de la caducidad alegada por ella para oponerse a la demanda impugnatoria del mismo, por lo que no procede estimar la excepción si, como en el caso, no se sabe cuándo se produjeron los despidos disciplinarios reconocidos como improcedentes; 4) son nulos todos los despidos producidos en el período de noventa días computable a efectos de determinar si ha habido o no un despido colectivo de hecho (en el caso, los que tuvieron lugar entre el 1 de febrero y el 30 de abril de 2013), sin que queden fuera del mismo los reconocidos como improcedentes y consensuados, ya que también les alcanza lo dispuesto en el art. 124.11 LJS y dado que no estamos ante un despido colectivo de hecho en fraude de ley (despido por goteo del art. $51.1 \mathrm{ET}$ ); 5) no es propio del litigio por despido colectivo determinar la incidencia que esa nulidad genera en esas transaccionales judiciales, debiendo resolverse en litigios individuales. 


\section{Causas de despido colectivo}

A) Alcance del control judicial sobre la concurrencia de la causa y sobre la justificación de la medida:

STS 18-2-14, Rec. 96/13; 26-3-14, Rec. 158/13; 15-4-14, Rec. 136/13; 25-6-14, Rec. 165/13);

STS 27-1-2014 R. 100/13 (razonabilidad), 25-6-14 R. 165/13.

La STS de 18 de julio de 2014 (RC 288/2013), Sala General, ratifica el ajuste a derecho del despido colectivo de 1.850 trabajadores de NCG Banco SA, iniciado en enero de 2013 y finalizado con acuerdo, al concurrir causa económica que lo justifica y no concurrir los defectos de tramitación alegados (ausencia de negociación y de entrega de la documentación exigida por el art. $51.2 \mathrm{ET})$.

B) El acuerdo en el período de consultas como elemento a tener en cuenta a la hora de apreciar la concurrencia de las causas: STS 25-6-14, Rec. 165/13

C) Solapamiento de medidas suspensivas y extintivas: STS 18-3-14 (Rec. 15/13)

La STS de 17 de julio de 2014 (RC 32/2014), Sala General, declara no ajustado a derecho, pero no nulo, el despido colectivo de 26 trabajadores de SIC Lázaro SL, iniciado en mayo de 2013 y finalizado sin acuerdo, dado que: 1) la no aportación de los criterios de selección de los afectados, aunque no se suple por el hecho de que se incluya relación expresa de afectados al iniciar el expediente, no ha generado indefensión en la negociación del mismo sobre dicho particular, a la vista del desarrollo de las negociaciones, sin que la nulidad prevista en el art. 124 LJS opere de forma automática por cualquier incumplimiento del deber de documentación ahí previsto; 2) no basta la mera concurrencia de causa para que el despido colectivo se ajuste a derecho, exigiéndose también que se cumplan criterios de adecuación y proporcionalidad, que en el caso de autos sí concurren; 3) la apreciación del carácter coyuntural o estructural de la causa en orden a determinar la procedencia de un ERTE suspensivo o un ERE extintivo es de apreciación empresarial, no controlable judicialmente, salvo abuso de derecho; 4) sin embargo, tramitado un ERTE suspensivo por unas causas (en el caso, productivas y tramitado sin acuerdo, con suspensión de contratos para toda la plantilla durante 42 días laborables a lo largo de 2013), no cabe alegar éstas más tarde para fundar un ERE extintivo, salvo que concurran circunstancias sobrevenidas e imprevisibles, lo que en el caso no se han dado y determinan la falta de ajuste a derecho de dicho despido. 
La STS de 24 de septiembre de 2014 (RC 271/2013), Sala General, confirma el ajuste a derecho del despido colectivo de toda la plantilla de Sucesores de Juan Villalón SL (sin acuerdo, iniciado en abril de 2013), al no obstar a ello que se haya promovido en mitad del período de cumplimiento de un ERTE con acuerdo (reducción de jornada y salario durante doce meses), al haberse agravado la situación determinante de este, al punto de haber sido declarada en concurso a solicitud efectuada ocho días después del despido. Recuerda la doctrina de la Sala en la materia, plasmada en STS de 12-Mz-14 (RCUD 673/2013), que exige aparición de nuevas causas o, cambio sustancial y relevante de la anterior.

La STS de 20 de noviembre de 2014 (RC 114/2014), Sala General. 1) No incurre en incongruencia omisiva la sentencia que sólo dirime la impugnación del despido colectivo de hasta 210 trabajadores de Unitono Servicios Externalizados SA, iniciado el 20 de marzo de 2013 y finalizado con acuerdo, pero no las de suspensión de contratos y reducción de jornada negociadas y adoptadas conjuntamente, si como en el caso sucede, se mandó des-acumular y, a consecuencia de ello, los sindicatos demandantes, no firmantes del acuerdo, optaron por mantener la impugnación del despido colectivo, presentando nuevas demandas, en las que se alcanzó acuerdo en conciliación; 2) la documentación contemplada en el art. 4.2 del R. Decreto 1483/2012, de 29-Oc, no es la única exigible, sino también toda la pertinente para el caso, en aplicación directa del art. 2.3 de la Directiva 98/59/CE del Consejo, de 20-Jl; 3) se ajusta a derecho dicho despido, sin que obste a ello: a) que las cuentas del último ejercicio (2012), auditadas, se entregaran en la última reunión (19 de abril de 2013) y no al inicio (en que se entregaron cuentas provisionales), ya que la exigencia del art. $4.2 \mathrm{del}$ R. Decreto 1483/2012, de 29-Oc, ha de interpretarse en conexión con los plazos de la regulación mercantil sobre aprobación de cuentas y plazo para emisión del informe de auditoría, sin que los demandantes pidieran, entonces, prórroga de plazo para su examen; b) los contratos con las empresas del grupo Telefónica (cuyo descenso de contratación se aducía como causa productiva) constituían documentación pertinente, si bien la negativa a entregarlos por razones de confidencialidad no determina la nulidad por incumplimiento del deber de documentación, ya que en las circunstancias del caso, en que se entregó trascripción parcial de los mismos, no impidió que tuvieran una adecuada información para negociar; c) se cumplió con la entrega de la documentación fiscal de los tres trimestres anteriores al inicio de los trámites del despido colectivo, prevista en el art. 4.4 de ese RD.

D) Causas económicas, técnicas, productivas y organizativas (ETOP): STS 25-6-14, Rec.165/13, 21-4-14, Rec. 126/13; y 27-5-13, Rec. 78/12

La STS de 17 de noviembre de 2014 (RC 79/2014), Sala General, confirma el ajuste a derecho del despido colectivo de la empresa Música y Es- 
cuelas SL, con cese de actividad, que afecta a sus 26 trabajadores, iniciado el 4-Mz-13 y sin acuerdo, dado que: 1) concurre causa económica, debido al descenso de alumnos en el curso escolar, con la disminución de los ingresos por matriculación, que le ha llevado a cesar en la gestión de la escuela municipal de música que llevaba a cabo, antes del vencimiento de la contrata; 2) no está obligado a subrogarse en dicho personal el Ayuntamiento de Valladolid, explotador directo del servicio hasta el curso 1996/1997 y titular del local donde se desarrolla la actividad y de su mobiliario (al que han revertido), dado que no implica sucesión de empresa, ya que no continúa con la actividad de la citada escuela ni era obligado que mantuviera el servicio.

La STS de 22 de diciembre de 2014 (RC 185/2014), Sala General, confirma el ajuste a derecho del despido colectivo de los 8 trabajadores integrantes de la plantilla Panadería Méndez Vegadeo SL por causas económicas, iniciado el 13 de diciembre de 2013 y sin acuerdo, dado que no prospera la revisión de hechos probados relativa a la situación económica de la empresa y que no se ha vulnerado por ésta el deber de negociar con buena fe, ya que no puede considerarse como incumplimiento del mismo que la empresa manifieste, en la primera reunión, que no tiene liquidez para abonar la indemnización propia del despido improcedente que, como única propuesta, hizo el delegado de personal, ante lo cual éste dio por rotas las negociaciones.

La STS de 28 de enero de 2015 (RC 87/2014), Sala General, confirma el ajuste a derecho del despido colectivo de 49 trabajadores de Ingeniería de Sistemas para la Defensa de España SA por causas organizativas, iniciado el 27-Jn-13 y sin acuerdo, no pudiendo declararse: 1) nulo, dado que se alega para ello una causa que no es de las legalmente previstas para esa calificación en el art. 124 LJS, ya que se limita a discutir el número de afectados en base a un informe técnico; 2) no ajustado a derecho, al quedar acreditado que, con ocasión de la fusión empresarial entre dicha sociedad y la sociedad estatal Ingeniería y Servicios Aeroespaciales SA, no sólo había 16 puestos duplicados sino también unas incoherencias que exigían un nuevo conjunto organizativo, del que resulta la supresión de los otros 33 puestos.

\section{E) Nuevas contrataciones: STS 21-5-14, Rec. 249/13 y 21-4-14, Rec. 126/13}

La STS de 29 de diciembre de 2014 (RC 93/2012), Sala General. 1) Confirma la nulidad del despido colectivo de 26 trabajadores de Halcón Foods SA, el 24-Ab-12, iniciado el 16 de ese mes, sin acuerdo, dado que: a) fue en fraude de ley, dado que los afectados eran fijos discontinuos y demandantes de resolución contractual ex art. 50 ET con juicio previsto para el 25-Ab-12 y sentencia estimada del 30 de ese mes, habiendo contratado la empresa a 76 trabajadores entre el 24 y $27-\mathrm{Ab}-12$; b) se incumplió el plazo mínimo de un mes para negociación; 2) en ese tipo de litigios, sujetos al RDL 3/2012, no procede condena al 
pago de salarios de tramitación, ya que son sentencias declarativas. En cuanto al punto 2, evoca la STS de 28-En-14 (RC 16/2013).

F) Incumplimiento de los compromisos de mantenimiento del empleo: STS 26-3-14, Rec. 86/12

\section{Despido colectivo y derechos fundamentales}

La STS 18-7-14 (Rec. 11/13, tema Celsa TSJPV), dictada tras la anulación de la previa de 20-9-13(Rec. 11/13). Sala General. Sr. Salinas. Voto particular. Declara que es nulo el despido colectivo de todos los trabajadores de dos de los centros de trabajo de Celsa Atlantic SA (Vitoria-Gasteiz y Urbina) por vulneración de los derechos fundamentales de huelga y libertad sindical, dado que dicho despido ha sido directa respuesta a la declaración y decisión colectiva de secundar una huelga indefinida por la plantilla de dichos centros, tras fracasar la negociación de un despido colectivo inmediato anterior que iba a afectar únicamente a parte de sus plantillas ( 91 trabajadores en total), finalmente no consumado y sustituido por el nuevo despido afectante a la totalidad de sus plantillas, con cierre de esos centros. El voto particular del Sr. Gilolmo, al que se adhiere otro magistrado, defiende que la nulidad afectaba únicamente al exceso de trabajadores afectados entre uno y otro despido, tal y como ya se resolvió por el propio TS en su sentencia de $20-\mathrm{Sp}-13$ dictada en este mismo RCUD, finalmente anulada por ATS de 26-Mz-14, y que, en realidad, la única razón de esa anulación y nuevo criterio ha sido el cambio de composición de la Sala.

En lo que respecta a la aplicación de criterios discriminatorios de selección de los trabajadores afectados, la STS 28-1-14 (Rec. 16/13). STS 18-2-14 (Rec. 96/13) en función de las circunstancias del caso. En relación a esa misma problemática tiene gran interés por sentar un criterio general la STS 25-6-14 (Rec. 198/13).

La STS 15-4-14 (Rec. 136/13), en la que se razona que la aplicación del test de proporcionalidad para el control de las limitaciones y restricciones de los derechos fundamentales.

La STS de 10 de febrero de 2015 (RC 221/2013), confirma la nulidad del despido colectivo de la plantilla de dos de los centros de trabajo de Loxam Alquiler SA, efectuado tras autorización administrativa de 30-Dc-11, previo acuerdo con la representación de los trabajadores, por vulneración de la garantía de indemnidad, en cuanto afecta a dos directivos con pacto individual de mejora indemnizatoria por ésta y otras causas de extinción de sus contratos, a los que se les había ofrecido excluirles de la relación de afectados si renunciaban a 
dicha mejora, lo que denunciaron a la Inspección de Trabajo durante la tramitación del ERE.

La STS de 23 de febrero de 2015 (RC 255/2013), Sala General. 1) Confirma la nulidad del despido colectivo de toda la plantilla de Printerman Industria Gráfica SA, iniciado el 4 de enero de 2013 y sin acuerdo, por vulneración del derecho de huelga, al ser reacción represiva al preaviso de huelga efectuado el 28 de diciembre de 2012; 2) confirma la condena solidaria de otras dos sociedades y del liquidador de todas ellas, como grupo de empresas patológico por su funcionamiento unitario, incluido el de sus plantillas; 3) confirma la legitimación de CGT para impugnar ese despido, dada su presencia en dicha empresa. El criterio se reitera en STS de 24-Fb-15 (RC 124/2014), en el caso del despido colectivo de toda la plantilla de otra empresa del grupo (Rotoencuadernación y Logísitica SL), iniciado el 21 de enero de 2013.

La STS 20 de abril de 2015 RC 354/2014, Sala General y VP (tema CocaCola). Contiene la última manifestación de declaración de nulidad de un despido colectivo por vulneración del derecho de huelga (durante el periodo de consultas)

\section{Procedimiento de despido colectivo}

\section{1.a) Fase colectiva}

\section{A) Aspectos previos}

a) Legitimación de los grupos de empresa patológicos para promover el procedimiento de despido colectivo: STS 25-6-14, Rec. 165/13, y 26-314, Rec. 158/13 La solución ya había sido anticipada por la STS 26-3-14 (Rec. 158/13). La STS de 23 de febrero de 2015 (RC 255/2013). Sala General: confirma la legitimación de CGT para impugnar ese despido, dada su presencia en dicha empresa. El criterio se reitera en STS de 24-Fb-15 (RC 124/2014), en el caso del despido colectivo de toda la plantilla de otra empresa del grupo (Rotoencuadernación y Logísitica SL), iniciado el 21 de enero de 2013.

b) Ámbito de negociación del despido colectivo afectante a dos o más centros de trabajo: STS 20-5-14 (Rec. 165/13)

c) Adaptación de la composición del banco social a los cambios en el ámbito subjetivo del despido colectivo. El principio de correspondencia: STS 2511-13 (Rec. 87/13 d) Composición de la comisión negociadora en supuestos de pluralidad de centros afectados, unos con representantes legales y otros sin ellos: STS 15-4-14, Rec. 127/13 y 1-4-14 (Rec. 95/13). 


\section{B) Iniciación del procedimiento}

a) Obligaciones informativas: TS 26-6-14, Rec. 219/13; 25-614, Rec. 273/13; 23-5-14, Rec. 179/13; 22-5-14, Rec. 17/14; 20-5-14, Rec. 276/13; 26-3-14, Rec. 158/13; 18-2-14, Rec. 74/13.

La STS de 2 de diciembre de 2014 (RC 97/2013), Sala General. Voto particular: Anula actuaciones desde la citación a juicio, en el litigio seguido por despido colectivo de 176 trabajadores del Ayuntamiento de Estepona, de julio de 2012, iniciado el 7 de junio de ese año, dado que se denegó indebidamente prueba pericial, alegando el TSJ su extemporaneidad porque no se solicitó con tiempo para poder efectuarla con cinco días de antelación al juicio, como lo exigía su complejidad, ya que no es obligado practicarla con esa antelación ni está legalmente prevista como causa de denegación en el art. 124.10 LJS si, como en el caso, se aporta con una menor (en el caso, el día anterior al del juicio), siendo así que dicha prueba puede resultar de utilidad, pertinencia y relevancia. El voto particular del Sr. Luelmo, al que se adhieren cinco magistrados, se opone a la estimación de ese motivo del recurso, considerándola bien denegada y no explicada tampoco la relevancia de dicha prueba. La STS de 9-Dc-14 (RC 222/2013) aplica el mismo criterio en un litigio sobre suspensión colectiva de contratos de trabajo en Cremonini Rail Ibérica SA, al considerar que el art. 82.4 LJS no impone un efecto preclusivo en la presentación de prueba documental o pericial compleja (en el caso, documental), máxime cuando el juicio se celebró con más de cinco días a la presentación de los documentos, dada la suspensión de la vista inicialmente fijada para fecha en que no habría transcurrido.

b) Obligaciones documentales: STS 20-3-13, Proc. 81/12; $27-$ 5-13, Rec. 78/12; 19-11-13, Rec. 78/13; 26-3-14, Rec. 158/13; 21-514, Rec. 249/13; 21-5-14, Rec. 1182/13; 23-5-14, Rec. 179/13; 26-6-14, Rec. 219/13).

La STS de 25 de febrero de 2015 (RC 145/2014), Sala General, confirma el ajuste a derecho del despido colectivo de 231 trabajadores de Capgemini España SL por causas económicas, iniciado el 26-Ab-13 y sin acuerdo, dadas las pérdidas millonarias en los últimos años, la ausencia de defectos relevantes en su negociación y en la entrega de la documentación (o su falta de denuncia en el período de consultas).

La STS de 20 de noviembre de 2014 (RC 114/2014), Sala General. 1) la documentación contemplada en el art. 4.2 del R. Decreto 1483/2012, de 29-Oc, no es la única exigible, sino también toda la pertinente para el caso, en aplicación directa del art. 2.3 de la Directiva 98/59/CE del Consejo, de 20-Jl;

2) se ajusta a derecho dicho despido, sin que obste a ello: a) que las cuentas del último ejercicio (2012), auditadas, se entregaran en la última reunión (19 de abril de 2013) y no al inicio (en que se entregaron cuentas provisionales), ya que 
la exigencia del art. 4.2 del R. Decreto 1483/2012, de 29-Oc, ha de interpretarse en conexión con los plazos de la regulación mercantil sobre aprobación de cuentas y plazo para emisión del informe de auditoría, sin que los demandantes pidieran, entonces, prórroga de plazo para su examen; b) los contratos con las empresas del grupo Telefónica (cuyo descenso de contratación se aducía como causa productiva) constituían documentación pertinente, si bien la negativa a entregarlos por razones de confidencialidad no determina la nulidad por incumplimiento del deber de documentación, ya que en las circunstancias del caso, en que se entregó trascripción parcial de los mismos, no impidió que tuvieran una adecuada información para negociar; c) se cumplió con la entrega de la documentación fiscal de los tres trimestres anteriores al inicio de los trámites del despido colectivo, prevista en el art. 4.4 de ese $\mathrm{RD}$.

La STS de 19 de noviembre de 2014 (RC 183/2014), Sala General. Voto particular: 1) conforme al art. 51.2 ET en su redacción vigente en junio de 2013, es un elemento constitutivo del despido colectivo la notificación, a la representación legal de los trabajadores, de la decisión que, tras finalizar el período de consultas sin acuerdo, finalmente adopta el empresario sobre el mismo, lo que no se ha dado en el caso del despido colectivo de 65 trabajadores de la sociedad mercantil de capital público Gestión Ambiental de Navarra SA (GANASA), iniciado el 7 de junio de 2013 y finalizado el 5 de julio siguiente, sin que ese requisito pueda entenderse cumplido por el hecho de que haya podido tener conocimiento de esa decisión por vía indirecta (en el caso, a través de correo electrónico remitido por la directora de recursos humanos de la corporación titular del $100 \%$ de su capital social, dando copia de la instancia remitida a la autoridad laboral notificando la decisión de GANASA); 2) el efecto jurídico de esa falta de notificación formal, cuando tiene lugar antes del 4-Ag-13, en que entra en vigor el RDL 11/2013, de $2-\mathrm{Ag}$, es el de la nulidad del despido colectivo, ex art. 124.11 LJS, y no el de caducidad del trámite, expresamente previsto en el art. 12.4 del R. Decreto 1483/2012, de 29 de octubre, dado que hasta esa reforma legal — que subsana el defecto- tenía carácter ultra vires esa norma reglamentaria y el último párrafo de su art. 12.1. El voto particular del Sr. López García de la Serrana, al que se adhirió otro magistrado, mantiene que el requisito en cuestión se cumplía con esa comunicación indirecta.

c) Obligaciones documentales de las empresas integradas en un grupo no patológico en los despidos por causas económicas: STS 27-5-13, Rec. 78/12.

\section{C) Tramitación del procedimiento: el periodo de consultas}

a) Medidas alternativas susceptibles de negociación: STS 19-3-14, Rec. 226/13.

b) Superación del plazo máximo de duración: STS 15-4-14, Rec. 188/13; 23-5-14, Rec. 179/13; 18-3-14, Rec. 125/13. 
La STS de 18 de julio de 2014 (RC 303/2013), Sala General, ratifica el ajuste a derecho del despido colectivo de 255 trabajadores de empresas del grupo CASER, iniciado el 21-Fb-13 y finalizado con acuerdo (que impugna un sindicato no firmante del mismo), toda vez que: 1) se ajusta a derecho que el período de negociación no haya agotado el plazo máximo de treinta días naturales legalmente dispuesto, dado el acuerdo alcanzado el día vigésimo tercero (art. 7.6 del RD 1483/2012, de 29 de octubre); 2) no se ha incumplido el deber de entrega de determinada documentación con defectos invalidantes, sin que obste a ello que la autoridad laboral requiriese a la empresa alguna, de carácter complementario y aportada durante una negociación finalizada con acuerdo; 3) en contra de lo que se alega, se aportaron los criterios de selección; 4) en consecuencia, no cabe negar que la negociación se ajustó a criterios de buena fe. El mayor interés de esta sentencia radica en que recopila criterios de la Sala sobre dichas cuestiones.

c) No vinculación de las propuestas realizadas en el período de consultas: STS 15-4-14, Rec. 188/13.

La STS de 22 de septiembre de 2014 (RC 305/2013), Sala General, ratifica el ajuste a derecho del despido colectivo de 350 trabajadores de Paradores de Turismo de Espańa SA, iniciado el 26-Nv-12 y finalizado con acuerdo, dado que: 1) no cabe calificarlo como nulo por defecto de legitimación de quienes lo negociaron en base a una causa que por vez primera se alega en fase de conclusiones del juicio oral y más cuando se rechazó ya entonces por el órgano judicial de instancia sin protesta; 2) no es contrario a la buena fe negociadora que en el convenio de empresa y en acuerdo previo al despido se hubiera pactado por el propio comité inter-centros que ha negociado éste, que no iba a haber despidos, dada: a) la situación de ultra-actividad del primero y la consideración de cláusula obligacional de aquélla; b) que el acuerdo estaba sujeto a una condición no cumplida (firma de un nuevo convenio); c) que el acuerdo en el despido colectivo se ha alcanzado con quienes firmaron el convenio y acuerdo invocados.

d) Significado y alcance de la obligación de negociar de buena fe: STS 20-3-13, Rec. 81/12; 27-5-13, Rec. 787/12; 28-1-14, Rec. 46/13; 18-2-14, Rec. 74/13; 18-3-14, Rec. 125/13; 26-3-14, Rec. 158/13; 11-414, Rec. 170/13; 15-4-14, Rec. 136/13; 21-4-14, Rec. 126/13; 20-5-14, Rec. 276/13; y 21-5-14, Rec. 249/13.

La STS de 20 de mayo de 2014 (RC 166/2013), Sala General. Voto particular: 1) es nulo el despido colectivo de doce trabajadores de Segur Ibérica SA en Navarra, iniciado en marzo de 2012 y finalizado sin acuerdo, dado que se vulneró el deber de negociar de buena fe, ya que la empresa simultaneó la negociación con contactos individuales con los afectados; 2) esa nulidad del despido no se extiende a la de los centros de trabajo de Bizkaia y Álava, en los que hubo acuerdo, dado que los demandantes (los delegados de personal del centro de $\mathrm{Na}$ - 
varra) no estaban legitimados para impugnarlo. Para entender bien el litigio, hay que partir de que el despido colectivo promovido por la empresa afectaba a trabajadores de los centros de trabajo ubicados en las tres provincias, desarrollándose negociaciones por separado en cada uno de ellos al no existir comité intercentros ni constituirse comisión ad hoc, finalizando con acuerdo en Bizkaia y Álava, pero no en Navarra. El voto particular de la Sra. Virolés defiende que, de oficio, debió declararse que la competencia del litigio no correspondía a la Sala de lo Social de la Audiencia Nacional sino a la del TSJ de Navarra.

\section{2. a) Fase individual}

Expresión de la causa en la carta individual de cese y puesta a disposición de la indemnización: TS 2-6-14 (Rec. 2534/13) 1) el requisito de notificación individual del despido colectivo en Capgemini España SL se cumple con una carta expresiva de la fecha de efectos de la extinción de su contrato de trabajo (en el caso, 9-Ab-12) y de que lo ha sido de conformidad con el acuerdo alcanzado con las secciones sindicales dentro del marco del ERE iniciado ante la Dirección General de Empleo el 5-Mz-12; 2) también se cumple el requisito de puesta a disposición de la indemnización si, conforme al acuerdo alcanzado en el despido colectivo, ésta es superior a la legal y se entrega en la fecha de efectos, habiéndose reconocido al trabajador en situación de permiso retribuido hasta esa fecha.

La STS de 25 de junio de 2014 (RC 198/2013), Sala General. Voto particular: se ajusta a derecho el despido colectivo de 300 trabajadores del Ayuntamiento de Jerez de la Frontera, iniciado el 16-Jl-12 y finalizado sin acuerdo, al concurrir causa económica en los términos exigidos en la disposición adicional vigésima del ET y ajustarse a derecho los criterios de selección de los trabajadores (en el caso, edad y evaluación continua), sin que la arbitrariedad que se denuncia en el modo de aplicar este último pueda valorarse en trámites de ese litigio, quedando reservada a los litigios individuales por despido que resulten de la impugnación individual por los afectados. El voto particular del Sr. Salinas, al que se adhieren otros cinco magistrados, defiende la nulidad del despido (y no su carácter de no ajustado a derecho, pronunciado en la sentencia recurrida), dada la falta de concreción de los criterios de selección (singularmente, el de evaluación continua), que no se puede suplir en los litigios individuales, en los que habrá de demandarse a quienes se consideren con menos méritos.

La STS de 25 de junio de 2014 (RC 273/2013), Sala General. No es nulo el despido colectivo de 232 trabajadores de Oesia Networks SL, iniciado en enero de 2013 y finalizado con acuerdo, por el hecho de que en el escrito de iniciación indicara como potenciales afectados por la extinción prevista a toda la plantilla, sin concretar categorías y centros, si como en el caso, la concreción se hizo en el curso de las negociaciones y finalizó con acuerdo, dado el carácter instrumental del requisito del art. 3.b) del RD 1483/2012. Recuerda sus preceden- 
tes de 28-My-13 (RC 78/2012) y 18-Fb-14 (RC 74/2013), aunque por lapsus, fecha la primera de ellas en el día 23 de mayo.

La STS de 23 de septiembre de 2014 (RC 231/2013), Sala General. Voto particular: declara no ajustado a derecho el despido colectivo de 77 trabajadores de la Agencia Pedro Laín Entralgo y sienta: 1) no es contrario al principio de igualdad que el despido afecte exclusivamente a los trabajadores temporales; 2) es inadecuado el proceso de despido colectivo para reclamar la prioridad de permanencia de los representantes de los trabajadores; 3) no se aprecia mala fe en las negociaciones; 4) en esta modalidad procesal no procede examinar si la notificación del despido a cada trabajador afectado cumple las exigencias del art. 53.1.a) ET; 5) ha habido sucesión de empresa entre dicha Agencia y la Comunidad de Madrid (Consejería de Sanidad), si bien por la Ley 4/2012 se excluido que ésta se subrogue en los contratos temporales; 6) el despido se ajusta a lo querido por la Ley autonómica; 7) la entidad de los problemas económicos no justifica un despido tan masivo como el realizado.

\section{Despido colectivo y grupo de empresas}

La cuestión fundamental que abordan es la relativa a la existencia de un concepto propio y diferenciado de "grupo de empresas» en el ámbito de las relaciones de trabajo, y a los elementos adicionales que pueden determinar. Este problema se trata en la STS 27-5-13 (Rec. 78/12) Esta doctrina se reitera en las STS 19-12-13 (Rec. 37/13) y 26-3-14 (Rec. 158/13). Es de notar que no obstante la precisión conceptual establecida por la sentencia cuya doctrina transcribe, esta última sentencia sigue partiendo de la distinción entre grupo de empresas a efectos mercantiles» $\mathrm{y}$ "grupo de empresas a efectos laborales».

Por su parte, la STS 25-9-13 (Proc. 3/13), niega que en el supuesto que decide exista un grupo de empresas a efectos laborales, razonando que, descartada cualquier conducta fraudulenta, la "confusión de patrimonios» no puede identificarse con el hecho de que una de las mercantiles que integran el grupo de sociedades tenga la práctica totalidad (el

99,97\%) del capital social de la que acordó el despido colectivo, y cuyo objeto social es totalmente ajeno a la actividad que realiza dicha empresa, conteniendo un interesante voto particular que posteriormente resumiremos. Tampoco se detecta patología alguna en los grupos que analizan las STS 20-5-14, Rec. 276/13 : confirma el ajuste a derecho del despido colectivo, sin acuerdo, de diez de los veintinueve trabajadores de El Día de Córdoba SLU, iniciado en septiembre de 2012, dado que no concurre en la empresa la alegada falta de buena fe en la negociación, se ha cumplido básicamente con el deber de fijar criterios de determinación de los afectados y se está ante una sociedad inserta en un 
grupo de empresas de carácter mercantil pero no laboral por no concurrir elementos reveladores de patología en su constitución societaria diversificada (Federico Joly y Compañía SL), y 21-5-14, Rec. 182/13.

La STS de 25 de junio de 2014 (RC 165/2013), Sala General. Se ajusta a derecho el despido colectivo, con acuerdo, de toda la plantilla del grupo de empresas laboral Teletech España, iniciado el 16 de julio de 2012, dado que: 1) estaba legitimado para plantearlo el propio grupo, en cuanto tal, sin que obste a ello que no estuviera prevista expresamente esa posibilidad en el Reglamento de Despidos Colectivos aprobado por RD 801/2011, de 10 de junio, aplicable al caso; 2) si bien la existencia del acuerdo, en los despidos colectivos (dada la ausencia, en los arts. 51 ET y 124 LJS, de una previsión análoga a la existente en el art. 47.1 ET para las suspensiones colectivas), no presume la concurrencia de la causa ni la razonabilidad y proporcionalidad del despido, los hechos acreditados revelan esa existencia, razonabilidad y proporcionalidad.

La STS de 23 de septiembre de 2014 (RC 66/2014), Sala General. Desestima el recurso de casación ordinario interpuesto contra la sentencia que declaró ajustado a derecho el despido colectivo en el grupo $\mathrm{NH}$ Hoteles (finalizado con acuerdo, alcanzando a 410 trabajadores), dado los defectos del escrito de formalización del recurso.

La STS de 22 de septiembre de 2014 (RC 314/2013), Sala General. 1) Confirma la nulidad del despido colectivo de trabajadores del Grupo Uribe (49 de Distribuidora Uribe SA y 94 de Supermercados Super Olé SA), iniciado el 27-Mz-12 y finalizado sin acuerdo, dado que: a) no es competente el juez del concurso si, como en el caso, la demanda por despido es posterior a la declaración de concurso y se dirige frente a empresas que lo están y otras que no lo están, no existiendo orden en contra del juez del concurso; b) no cabe examinar las infracciones denunciadas sobre los requisitos formales del ERE, dado que únicamente se menciona una norma amplísima (RD 801/2011), sin concreción de preceptos; 2) confirma la condena solidaria de las nueve sociedades demandadas, como grupo laboral, al concurrir un uso fraudulento de la personalidad jurídica, revelado por la existencia de una empresa que gestiona a todas con caja única y empleando las empresas indistintamente a trabajadores de cualquiera de ellas.

La STS de 20 de noviembre de 2014 (RC 73/2014), Sala General, declara que es nulo el despido colectivo de 49 trabajadores de tres sociedades que se reconocen como grupo laboral (SANCA, Servicios Generales a la Comunicación SA, GESFIMA SAL y COPLAIN SA), iniciado el 4-Mz-13, basado en causas económicas y sin acuerdo, si resulta que, como aquí sucede, el grupo laboral lo integraban también otras tres sociedades.

La STS de 29 de diciembre de 2014 (RC 83/2014), Sala General, desestima el recurso del SEPLA (38 motivos) y confirma el ajuste a derecho del des- 
pido colectivo de 35 trabajadores de Binter Canarias SA, iniciado el 9-Ab-12, con acuerdo, con indemnizaciones de 45 días/año sin tope para quienes tuvieran salario no superior a 40.000 euros/año y de 20 días/año, con tope de doce mensualidades, a quienes lo rebasaran, dado que: 1 ) no debió hacerse negociación diferenciada por franja (pilotos); 2) aunque esa empresa se integra en un grupo societario, no es patológico y por ello no tiene la condición de empresario; 3) no se han vulnerado los deberes de documentación y negociación de buena fe; 4) no es abusivo ni discriminatorio esa diferencia de criterio indemnizatorio.

La STS de 23 de febrero de 2015 (RC 255/2013), Sala General, confirma la condena solidaria de otras dos sociedades y del liquidador de todas ellas, como grupo de empresas patológico por su funcionamiento unitario, incluido el de sus plantillas; confirma la legitimación de CGT para impugnar ese despido, dada su presencia en dicha empresa. El criterio se reitera en STS de 24-Fb-15 (RC 124/2014), en el caso del despido colectivo de toda la plantilla de otra empresa del grupo (Rotoencuadernación y Logísitica SL), iniciado el 21 de enero de 2013.

\section{Impugnación del despido colectivo}

\section{A) Acción colectiva social}

1) Adecuación del procedimiento de despido colectivo para impugnar los despidos colectivos de hecho: 25-11-13 (Rec. 52/13).

2) Ámbito de cognición del procedimiento de despido colectivo: STS 256-14, Rec. 198/13; 21-5-14, Rec. 183/13.

La STS de 29 de octubre de 2014 (RCUD 3065/2013). La indemnización por un despido colectivo improcedente producido tras la vigencia del RDL 3/2012, de 10 de febrero (en el caso, el 18 de octubre de 2012), de quien fue contratado antes de esa vigencia y tenía, a su entrada en vigor más de dieciséis años de antigüedad computable (en el caso de las dos despedidas, el 18 de marzo de 1980 y el 3 de octubre de 1989), no está topada en los 720 días de indemnización del art. $56 \mathrm{ET}$, debiendo calcularse conforme a lo dispuesto en el apartado 2 de la disposición transitoria quinta de ese RDL (lo que en el caso supone el tope de 42 mensualidades para la primera y de 1030 días para la segunda).

La STS de 27 de enero de 2015 (RC 189/2014), Sala General. 1) Conforme al art. 64.1 de la Ley Concursal, corresponde enjuiciar a los órganos específicos del orden social (en el caso, Sala de lo Social de la Audiencia Nacional) y no al Juez del concurso, la demanda impugnando el despido colectivo adoptado por la empresa días antes de su declaración en concurso y aunque la demanda se haya presentado tras esa declaración; 2) es nulo el despido colectivo 
de 80 trabajadores de Arción SA Construcciones, iniciado en marzo de 2013 y adoptado el 8-Jl-13, sin acuerdo, dado el modo en que se negoció (múltiples mesas negociadoras, conformadas por comisiones híbridas, no conformadas con el consentimiento de los representantes legales de los trabajadores existentes en algunos de los múltiples centros de trabajo), ya que tampoco se ajustó a la previsión de negociación por centros contemplada en el art. 26 del R. Decreto 1483/2012, de 29 de octubre. El criterio 1) también se aplica en STS de 26-En-15 (RC 173/2014), de Sala General, relativo al despido colectivo de toda la plantilla de Teleinformática, Datos y Comunicaciones SA (DATELSA), siendo la única cuestión planteada en ese recurso de casación.

La STS de 2 de diciembre de 2014 (RC 99/2014), confirma el ajuste a derecho del despido colectivo de los 19 trabajadores de Espato de Villabona SA por causas económicas y productivas, iniciado el 13 de septiembre de 2013 y sin acuerdo, sin que pueda reputarse efectuado en fraude de la verdadera naturaleza que debería tener su crédito indemnizatorio (crédito contra la masa), ya que no se ha acreditado que la empresa estuviera en la situación de concurso necesario que le habría obligado a instarlo y, con ello, tramitarse la extinción por el Juez del concurso.

3) Plazo de ejercicio de la acción: STS 15-4-14, Rec. 188/13 y 19-3-14, Rec. 226/13.

4) Legitimación activa de las comisiones ad hoc: STS 18-3-14 (Rec. 114/13).

La STS de 22 de septiembre de 2014 (RC 27/2014), Sala General, confirma el ajuste a derecho del despido colectivo de 37 trabajadores de Ros Casares Centro del Acero SLU, iniciado el 7-Mz-13 y finalizado sin acuerdo, toda vez que: 1) no es invalidante su híbrida comisión negociadora con representantes legales y representantes ad hoc, dado que no puede considerarse que la previa modificación de la estructura del grupo empresarial se hizo para alterar la composición del banco social en dicha comisión; 2) no se vulneró el deber de negociar de buena fe por el hecho de que se haya reducido notablemente el número de despedidos respecto a la propuesta inicial de la empresa, sin que pueda estimarse injustificada ésta; 3) no se vulnera el deber de documentación por el hecho de que algunos documentos se aportaran en la última reunión (plan de viabilidad y cuentas provisionales de 2012), ya que no se pidió por el banco social más tiempo para su examen; 4) concurren causas económicas y productivas que justifican los despidos.

5) Falta de legitimación activa de los trabajadores afectados STS 26-12-13, Rec. 28/13.

La STS de 24 de junio de 2014 (RC 297/2013), Sala General. No está legitimado para impugnar un despido colectivo un sindicato estatal sin pre- 
sencia en sus órganos de representación unitaria y no constando con más presencia en la empresa que la de tener constituida una sección sindical en uno de sus centros ni más afiliado que una persona, dado que con ello no cumple el requisito de tener implantación suficiente en el ámbito en que se produjo el despido, exigido en el art. 124.1 LJS (en el caso, CGT, respecto al despido colectivo en Alten Servicios, Productos, Auditoría e Ingeniería SAU iniciado en diciembre de 2012, que afectó a ciento treinta y cinco trabajadores, finalizando con acuerdo). La sentencia menciona, como precedente, la STS de 20-Mz-12 (RC 71/2010), si bien ésta no se dictó en litigio de impugnación de despido colectivo, sino en uno de conflicto colectivo, aplicando el art. 152.a) LPL. De sus fundamentos no se extrae una doctrina que permita conocer qué entiende la Sala por «implantación suficiente en el ámbito del despido colectivo».

La STS de 25 de febrero de 2015 (RC 36/2014), Sala General. Carece de legitimación para impugnar un despido colectivo (en el caso, el de T-Systems Eltec SLU), un delegado de personal cuando la representación unitaria de los trabajadores la integran tres delegados, al no ser la mayoría y ejercer su facultad mancomunadamente, conforme al art. 62.2 ET.

La STS de 25 de febrero de 2015 (RC 202/2014), Sala General. La CGT no está legitimada para interponer demanda impugnando el despido colectivo de Roca Sanitario SA (iniciado el 25-Jn-13 y finalizado con acuerdo), dado que éste afecta únicamente a trabajadores de dos de sus cuatro centros de trabajo, en los que ese sindicato no tiene representantes unitarios, sin que obste a ello que los tenga en los otros centros, por lo que no reúne el requisito de implantación suficiente en el ámbito del despido colectivo, que exige el art. 124.1 LJS. Sigue el criterio aplicado en STS de 21-Oc-14 (RC 11/2014), en el litigio seguido por el primer despido colectivo en dicha empresa (sin acuerdo, finalizado con sentencia que lo declaró nulo).

La STS de 28 de enero de 2015 (RC 35/2014), Sala General, comenta que a tenor de los arts. 17.2 y 155 LJS y art. 13 LEC, pese a la falta de norma específica en el art. $124 \mathrm{LJS}$, están legitimados para intervenir en el litigio de despido colectivo finalizado sin acuerdo (en el caso, el de Santa Bárbara Sistemas SA) tres sindicatos no demandantes (en el caso, CCOO, UGT y CSI-CSIF), llamados al mismo como interesados por uno de los sindicatos demandantes, compareciendo al juicio en donde se adhirieron a la demanda, debiendo anularse la sentencia recurrida que les niega esa legitimación (en el caso, de la Audiencia Nacional), reponiendo el curso del litigio para que dicte nueva sentencia teniendo en cuenta sus alegaciones y prueba.

6) Medios de prueba TS 18-3-14, Rec. 114/13; 20-5-14, Rec. 168/13; 235-14, Rec. 179/13. 
7) Contenido del fallo de la sentencia En este punto se han planteado varias interrogantes que han sido despejadas por el TS:

a) La posibilidad de declarar ajustada la medida en relación a parte de los trabajadores afectados: STS 15-4-14, Rec. 136/13.

b) Calificación de la decisión extintiva adoptada en fraude de ley, o con dolo, coacción o abuso de derecho: STS 17-2-14, Rec. 142/13 y 143/13 y 266-14, Rec. 219/13.

La STS de 25 de junio de 2014 (RC 223/2013), Sala General. 1) El despido colectivo de toda la plantilla del Consorcio de la Unidad Territorial de Empleo, Desarrollo Local y Tecnológico de Alto Guadalquivir, el 5 de octubre de 2012, se ha efectuado en fraude de ley, en cuanto destinado a evitar la subrogación legal de esos trabajadores por la Agencia Servicio Andaluz de Empleo, dispuesta en el art. 8.5 y disposición adicional cuarta.1 de la Ley autonómica 1/2011, de 17 de febrero, en relación con la disposición adicional segunda del Decreto autonómico 96/2011, de 19 de abril, y el protocolo de integración aprobado por resolución de la Secretaría General de la Administración Pública de la Junta de Andalucía, ya que lo adecuado habría sido disolver el Consorcio y producir con ello, automáticamente, el supuesto legal para esa subrogación; 2) son nulos los despidos colectivos en fraude de ley impugnados colectivamente, ya que la ausencia de previsión legal de la calificación de tales despidos debe suplirse aplicando el art. 6.4 del Código Civil y a ello conduce también su antecedente histórico, la misma calificación a realizar cuando la impugnación del despido colectivo en fraude de ley es individual y la incoherencia que supone la previsión específica de nulidad para defectos menos relevantes como son los de procedimiento; 3) esa nulidad lleva consigo, en el caso, la condena solidaria del referido Consorcio y el Servicio Andaluz de Empleo. Sigue la STS de 18-Fb-14 (RC 115/2013)

c) Irregularidades que no justifican la declaración de nulidad del despido. STS 18-3-14 R. 125/13.

d) Naturaleza de la sentencia que declara la nulidad del despido. STS 28-14 R. 16/13 y ATS 23-7-13 RQ 8/13. La STS 20 de abril de 2015 RC 354/2014. Sala General y VP (tema Coca-Cola), contiene la última manifestación de declaración de nulidad de un despido colectivo por vulneración del derecho de huelga (durante el periodo de consultas) y se pronuncia sobre la necesidad de consignar el importe de la condena si se declara nulo el despido colectivo.

La STS de 29 de diciembre de 2014 (RC 93/2012), Sala General. 1) Confirma la nulidad del despido colectivo de 26 trabajadores de Halcón Foods $\mathrm{SA}$, el 24-Ab-12, iniciado el 16 de ese mes, sin acuerdo, y dice que en ese tipo de litigios, sujetos al RDL 3/2012, no procede condena al pago de salarios de tramitación, ya que son sentencias declarativas. Evoca la STS de 28-En-14 (RC 16/2013). 
8) Sector Público: STS de 24 de febrero de 2015 (RC 165/2014), Sala General. Confirma el ajuste a derecho del despido colectivo iniciado en el Ayuntamiento de Aljaraque y finalizado con acuerdo, dado que: 1) lo negoció el comité de empresa, que está legitimado para ello, sin que debiera haberlo sido por las secciones sindicales, dado que no hubo acuerdo de éstas con presencia mayoritaria en aquél para asumirlo ellas (art. 51.2 ET); 2) no obsta que lo acordase el Alcalde, sin ratificación por el Pleno del Ayuntamiento, ya que no se exige ésta, al haberse derogado la previsión contenida en el art. 50.10 del R. Decreto $2568 / 1986$; 3 ) no es alegable en esta modalidad procesal la prioridad de permanencia de los representantes de los trabajadores; 4) no hay vulneración de la garantía de indemnidad ni de los derechos de libertad sindical, no discriminación y huelga en la selección de afectados, pese a los indicios existentes respecto a alguno de ellos, dado que lo han sido en función de unos criterios objetivos pactados que desvirtúan la existencia de esa vulneración; 5) a la vista de los hechos probados y con el refuerzo que, a estos efectos, supone la existencia del acuerdo, concurre el requisito de insuficiencia presupuestaria sobrevenida y persistente para la financiación de los servicios públicos, constitutivo de causa económica en este ámbito, y también causa organizativa; 6) no ha habido incumplimiento del deber de negociar con buena fe; 7) la posible ilegalidad de alguna de las estipulaciones pactadas sobre jubilación parcial, contrato de relevo y complemento de prestaciones por desempleo no es constitutiva, sin más, de abuso de derecho o fraude de ley. La sentencia contiene un análisis exhaustivo de los diversos problemas que plantea la causa económica en el ámbito del sector público, que si bien reitera lo que se expuso en STS de 2-Dc-14 (RC 29/2014).

Antes la STS de 3 de diciembre de 2014 (RC 201/2013), Sala General con Voto particular concurrente: 1) confirma el ajuste a derecho del despido colectivo de toda la plantilla de la Fundación de Servicio Valenciano de Empleo, iniciado el 30-Nv-12 y sin acuerdo, por haberse acordado la extinción de la Fundación, ante la imposibilidad de cumplir su fin fundacional por falta de previsión presupuestaria para 2013, en aplicación de la reestructuración del sector público acordada por el órgano de gobierno de la Comunidad Valenciana en razón a la limitación presupuestaria establecida en la Ley Orgánica 2/2012; 2) no obsta a esa calificación la ausencia del informe técnico previsto en el art. 4.3 del R. Decreto 1483/2012, dado que el despido colectivo no se sustenta en la previsión de pérdidas y, en todo caso, no habría impedido la negociación con conocimiento de la causa que se esgrimía; 3) en los despidos por extinción de la personalidad jurídica ex art. 49.1.g) ET basta con que se esté ante un supuesto legal que la imponga (como en el caso: imposibilidad de realizar el fin fundacional -art. 33 de la Ley 50/2002, de 26 de diciembre, de Fundaciones-), sin necesidad de que concurran causas propias del despido colectivo (únicamente exigibles cuando la decisión extintiva sea voluntaria, a fin de evitar una conducta constitutiva de fraude de ley o abuso de derecho), radicando el control judicial 
en la comprobación de la validez de la extinción de la personalidad jurídica y la ausencia de fraude de ley o abuso de derecho en la misma. El mayor interés de la sentencia radica en la doctrina del punto 3), en relación a lo cual recuerda cómo en STS de 26-Jn-14 (RC 219/2013) declaró la nulidad de un despido colectivo basado en la extinción de la personalidad jurídica por fraude de ley, ya que se adoptó para evitar los efectos de subrogación del art. $44 \mathrm{ET}$. El voto particular del Sr. Salinas y otros tres magistrados comparte el pronunciamiento pero considera que no debía haberse sentado la doctrina del punto 3) con ese carácter general, que por lo demás considera opuesto a la doctrina expresada en ese antecedente, en la que se manifestaba que la remisión a los trámites del despido colectivo era también a su aspecto sustantivo. Ni la sentencia aprobada ni el voto mencionan la STS de 23-Sp-14 (RC 52/2014) dictada en otro caso de despido colectivo por extinción de la personalidad jurídica de la Fundación de la Solidaridad y el Voluntariado de la Comunidad Valenciana en junio de 2013.

Y la STS de 2 de diciembre de 2014 (RC 29/2014), Sala General. Confirma el ajuste a derecho del despido colectivo de 35 trabajadores del Ayuntamiento de Totana, el 29-Nv-12, iniciado el 17 de octubre de ese año, sin acuerdo global, aunque sí parciales, por concurrir causas económicas y organizativas, al existir una situación de insuficiencia presupuestaria sobrevenida y persistente que afecta a la financiación de sus servicios públicos, como lo exige la disposición adicional vigésima del Estatuto de los Trabajadores, siendo una medida adecuada y proporcionada.

También la STS de 23 de septiembre de 2014 (RC 52/2014), Sala General. Confirma el ajuste a derecho del despido colectivo de toda la plantilla (= 18 trabajadores) de la Fundación de la Solidaridad y el Voluntariado de la Comunidad Valenciana por extinción de su personalidad jurídica por causas económicas, iniciado el 4-Jn-13 y finalizado sin acuerdo, dado que: 1) concurre causa económica, ya que sus únicos ingresos procedían de las subvenciones de sus patronos (Bancaja y la Generalitat Valenciana), habiéndose extinguido la primera en 2012 sin que sea reprochable a la Fundación que no pudiera cobrar una subvención de 494.200 euros que aquélla había concedido en 2011, y sin que sea exigible a la segunda que aporte más subvenciones que las que decidió dar en 2012 y, ya en julio de 2013, otra para financiar la extinción y liquidación de la entidad; 2) es cuestión nueva la alegación de falta de buena fe en la negociación, que en todo caso se formula defectuosamente en el recurso y sin base en los hechos probados, ya que constan propuestas con mejoras de indemnización y para facilitar la recolocación. El voto particular de la Sra. Virolés, al que se adhieren tres magistrados, defiende que el despido debió declararse no ajustado a derecho por considerar que no se negoció de buena fe, ya que la extinción de la Fundación se había decidido previamente al inicio del despido colectivo, sin que se haya acreditado que la misma no pudiera mantener su actividad con las subvenciones de la Generalitat, tras la reducción de plantilla y de jornada efec- 
tuada en 2012 en trámites de un previo despido colectivo de parte de la plantilla, al dejar de ser patrono Bancaja.

La STS de 26 de junio de 2014 (RC 219/2013), Sala General. Voto particular: 1) confirma la nulidad del despido colectivo efectuado el 13 de diciembre de 2012 por la Agencia de Protección de Datos de la Comunidad de Madrid, sin acuerdo, iniciado el 28 de noviembre de ese ańo, que ésta fundaba en la extinción de su personalidad jurídica prevista en el art. 55 del Proyecto de Ley de la Comunidad de Madrid, de Medidas Fiscales y Administrativas para 2013, dado que se adopta antes de producirse dicha extinción, no invoca causa concreta del art. 51.1 ET ni se aporta la documentación prevista al efecto, sin que pueda estimarse como tal la transferencia de su actividad a la Comunidad de Madrid; 2) confirma la condena solidaria de la Comunidad de Madrid, dado que se está ante un supuesto de fraude de ley para evitar la subrogación. El voto particular del Sr. López García de la Serrana defendía que el despido debió declararse no ajustado a derecho por falta de causa y sin responsabilidad solidaria de la Comunidad por no existir fraude de ley en la actuación de ésta.

B) Acción colectiva empresarial: STS 26-12-13, Rec. 28/13).

Acción de jactancia

La STS de 22 de diciembre de 2014 (RC 81/2014), Sala General. Voto particular concurrente: de oficio, aprecia falta de legitimación activa de la empresa demandante (Sdad CRS SA) y de legitimación pasiva de los demandados (los cinco miembros de su comité de empresa, a título individual), en litigio promovido por la primera, ex art. 124.3 LJS, pretendiendo que se declare ajustado a derecho el despido colectivo de toda su plantilla, iniciado el 29 de octubre de 2012 y finalizado con acuerdo, ya que esta modalidad procesal, a iniciativa empresarial, ha de dirigirse frente a sujeto colectivo que se oponga a su pretensión. Recuerda su precedente de 26-Dc-13 (RC 28/2013). El voto particular de la Sra. Arastey comparte la desestimación de la demanda, aunque por falta de acción, en cuanto considera que el empresario nunca puede demandar por este cauce procesal, cuando ha habido acuerdo.

La STS de 22 de diciembre de 2014 (RC 316/2013), Sala General, confirma el ajuste a derecho del despido colectivo de la totalidad de la plantilla del Patronato del Parador de Turismo de Fuerteventura, iniciado el 8-Fb-13 y sin acuerdo, y con ello la estimación de la demanda interpuesta por ésta ex art. 124.3 LJS, dado que concurre causa económica para ello (gran déficit de explotación del parador que constituye la única actividad del Patronato), tiene personalidad diferenciada al Cabildo Insular de Fuerteventura sin que haya base para atribuir la condición empresarial a éste, no habiéndose infringido los deberes de documentación y negociación de buena fe. Si destaco esta sentencia es únicamente porque, según creo, es la primera en la que el Tribunal Supremo no pone reparo 
formal alguno a la demanda empresarial ex art. 124.3 LJS e, incluso, confirma su estimación, a diferencia de lo que sucede en la anterior RC 81/2014.

\section{C) Acción de oficio}

TSJ Valladolid 9-10-13, Rec.1234/13. TSJ C. Valenciana 7-5-13, Proc. 12/13; y 8-5-14, Proc. 10/14.

\section{D) Acción individual}

La STS de 23 de septiembre de 2014 (RC 231/2013), Sala General. Voto particular, declara no ajustado a derecho el despido colectivo de 77 trabajadores temporales de la Agencia Pedro Laín Entralgo y sienta: 1) no es contrario al principio de igualdad que el despido afecte exclusivamente a los trabajadores temporales, dado que es efecto de lo dispuesto en la disposición adicional tercera de la Ley 4/2012, de 4 de julio, de la Comunidad de Madrid, que a su vez se atiene a lo establecido en el último párrafo de la disposición adicional vigésima del Estatuto de los Trabajadores; 2) es inadecuado el proceso de despido colectivo para reclamar la prioridad de permanencia de los representantes de los trabajadores; 3) no se aprecia mala fe en las negociaciones; 4) en esta modalidad procesal no procede examinar si la notificación del despido a cada trabajador afectado cumple las exigencias del art. 53.1.a) ET; 5) ha habido sucesión de empresa entre dicha Agencia y la Comunidad de Madrid (Consejería de Sanidad), si bien por la Ley 4/2012 se ha excluido que ésta se subrogue en los contratos temporales, en regla ajustada a la mencionada disposición adicional $20{ }^{a}$ ET; 6) el despido se ajusta a lo querido por la Ley autonómica; 7) la entidad de los problemas económicos no justifica un despido tan masivo como el realizado, al no concurrir el requisito de razonable adecuación entre la causa y la decisión extintiva. El voto particular de la Sra. Segoviano, al que se adhieren otros cinco magistrados, defiende la nulidad de los despidos por estimar que el despido colectivo debió negociarse con la Comunidad de Madrid y aportando ésta la documentación requerida por el art. 52.1 ET.

\section{Bibliografía}

Benito-Butrón OchoA, Juan Carlos: «Extinción por causas objetivas y despido colectivo». Curso Especialista en Derecho Laboral y Seguridad Social. Colegio de Abogados de Vizcaya (ICASB) 13 Febrero de 2015.

Díaz de Rábago, Manuel: "Comentarios de STS». Foros Sociales de Thomson-Reuters Aranzadi. Cursos 2012 a 2015.

Palomo Balda, Emilio: «Criterios Judiciales en materia de despidos objetivos y colectivos. Aspectos sustantivos y procesales». Ponencia-charla CGPJ 2 de octubre de 2014.

«Reciente doctrina judicial sobre despidos por causas empresariales». Foro Social Thomson-Reuters Aranzadi Febrero de 2015. 